\title{
Vertebral Artery Dissection: Warning Symptoms, Clinical Features and Prognosis in 26 Patients
}

\author{
Abdullah Bin Saeed, Ashfaq Shuaib, Ghanem Al-Sulaiti and Derek Emery
}

\begin{abstract}
Background and objectives: Internal carotid artery dissection has been extensively studied and well-described. Although there has been a recent increase in the number of reported cases of vertebral artery (VA) dissection, the clinical variety of presentation and the early warning symptoms have not been well-described before. Our objectives in this study include: (1) To determine the early symptoms and warning signs which may help the clinician in the early identification and treatment of patients with VAdissection. (2) To explore the variety of clinical presentation of VA dissection and its relation to prognosis. Design and setting: Retrospective analysis of hospital records in a tertiary academic centre for the period 1989-1999. Results: Twenty-six patients were identified (13 men and 13 women). The mean age was 48. Possible precipitating factors were identified in 14 patients (53\%). Sporting activity and chiropractic manipulations were the most common (15\% and $11 \%$ respectively). Headache and/or neck pain was the prominent feature in $88 \%$ of patients and was a warning sign in 53\%, preceding onset of stroke by up to 14 days. The most common clinical features included vertigo (57\%), unilateral facial paresthesia (46\%), cerebellar signs (33\%), lateral medullary signs (26\%) and visual field defects (15\%). Bilateral VA dissection presented in six patients (24\%). The most common region of dissection was the C1-C2 level (16 arteries, $51 \%)$. Intracranial VAdissection was found in eight arteries (25\%). The majority of patients (83\%) had favorable outcome. Poor prognosis was associated with (1) bilateral dissection; (2) intracranial VA dissection accompanied by subarachnoid hemorrhage. Only two patients reported stroke recurrence. Conclusions: Our findings show that VA dissection affects mainly middle age persons and involves both sexes equally. Headache and/or neck pain followed by vertigo or unilateral facial paresthesia is an important warning sign that may precede onset of stroke by several days. Although the majority of patients will have excellent prognosis, this was less likely in patients presenting with subarachnoid hemorrhage or bilateral VA dissection. Recurrence rate was low.
\end{abstract}

RÉSUMÉ: Dissection de l'artère vertébrale: symptômes d'alerte, caractéristiques cliniques et pronostic chez 26 patients. Introduction et objectifs: La dissection de la carotide interne a fait l'objet de nombreuses études et a été bien décrite. Bien qu'il y ait une augmentation récente du nombre de cas de dissection de l'artère vertébrale (AV) rapportés, le spectre de la présentation clinique et les symptômes d'alerte précoces n'ont pas encore été bien décrits. Les objectifs de cette étude sont les suivants: (1) déterminer les symptômes précoces et les signes d'alerte qui peuvent aider le clinicien à identifier et traiter précocement les patients porteurs d'une dissection de l'AV; (2) explorer le spectre de la présentation clinique de la dissection de l'AV et sa relation au pronostic. Plan et contexte: Il s'agit d'une analyse rétrospective de dossiers hospitaliers dans un centre académique tertiaire de 1989 à 1999. Résultats: Vingt-six patients ont été identifiés (13 hommes et 13 femmes). L'âge moyen était de 48 ans. Des facteurs précipitants possibles ont été identifiés chez 14 patients (53\%). Les activités sportives et les manipulations de chiropractie étaient les facteurs les plus fréquents ( $15 \%$ et $11 \%$ respectivement). Une céphalée et/ou une douleur cervicale étaient les symptômes dominants chez $88 \%$ des patients et étaient un signe d'alerte chez 53\%, précédant le début de l'accident vasculaire cérébral (AVC) d'un laps de temps pouvant aller jusqu'à 14 jours. Les caractéristiques cliniques les plus fréquentes étaient le vertige (57\%), la paresthésie faciale unilatérale (46\%), des signes cérébelleux (33\%), des signes médullaires latéraux (26\%) et des déficits du champs visuel (15\%). Six patients (24\%) présentaient une dissection bilatérale de l'AV. La région la plus fréquemment touchée était le niveau C1-C2 (16 artères, 51\%). Une dissection intracrânienne de l'AV a été mise en évidence dans huit artères (25\%). La majorité des patients $(83 \%)$ ont eu une évolution favorable. Un pronostic défavorable était associé à (1) une dissection bilatérale; (2) une dissection intracrânienne de l'AV accompagnée d'une hémorragie sous-arachnoïdienne (HSA). Seulement deux patients ont eu une récidive de l'AVC. Conclusions: Nos observations démontrent que la dissection de l'AV affecte surtout des personnes d'âge moyen et atteint les deux sexes également. La céphalée et/ou la cervicalgie suivie de vertiges ou de paresthésie faciale unilatérale est un signe d'alerte important qui peut précéder le début de l'AVC de plusieurs jours. Bien que la majorité des patients ont un excellent pronostic, pour ceux qui présentent une HSAou une dissection bilatérale de l'AV le pronostic est plus sombre. Le taux de récidive était faible chez les patients étudiés.

Can. J. Neurol. Sci. 2000; 27: 292-296

The incidence of cervical artery dissection is unknown. In some series of young patients with stroke, dissection accounts for one fifth to one tenth of cases. ${ }^{1}$ Internal carotid artery dissections are widely-known and as a diagnosis are more often sought. ${ }^{2,3}$ Although there has been a recent increase in the
From the Department of Medicine, Division of Neurology (A.B.S., A.S., D.E.) and Neurosurgery (G.A.-S.), University of Alberta, AB, Canada

ReCEIVED DeCEMber 7, 1999. ACCEPTED INFinAlform February 29, 2000. Reprint requests to: Ashfaq Shuaib, Professor of Medicine and Director of Neurology, University of Alberta Hospital, Rm 2E3.13, Edmonton, AB T6G 2B7 Canada. 
number of reported cases of vertebral artery (VA) dissection, a study of the patients presented in this report show that VA dissection diagnosis is frequently not considered in the younger patient with typical symptoms. In many instances, the diagnosis in patients with multiple suggestive symptoms is missed until after stroke develops. Our objectives of presenting this series include identifying the early symptoms that should raise suspicion of VA dissection, explore the variety of clinical presentation of VAdissection, and to evaluate the prognosis and frequency of recurrence.

\section{SUBJECTS AND METHODS}

We reviewed and studied medical records of all patients less than age 60 with stroke and all patients who underwent cerebral angiography between 1989-1999 at the University of Alberta Hospital, Edmonton. We excluded patients with traumatic arterial dissection and patients with only occlusion of a VA on angiograms without angiographic evidence of dissection in the other VA. Twenty-six consecutive patients with VA dissection were identified. We studied their demographic features; presence or absence of warning symptoms; cumulative symptoms and signs; the presence of predisposing factors; the prevalence of diabetes mellitus, hypertension or migraine; neuroimaging and angiographic findings and type of treatment received. All patients, except one, had standard four vessel cerebral angiography within five days of stroke onset. One patient was diagnosed with magnetic resonance angiography. Follow-up was possible in twenty patients. The duration of follow-up ranged from four weeks to five years. For the purpose of classification we used a simple four category outcome scale:

Table 1: Cumulative symptoms*

\begin{tabular}{lll}
\hline Symptom & No. of Patients & Approx. Percentages \\
Pain & 22 & $88 \%$ \\
$\quad$ Only neck pain & 4 & $15 \%$ \\
$\quad$ Only headache & 13 & $50 \%$ \\
$\quad$ Both & 5 & $19 \%$ \\
& & \\
Headache by location: & 12 & \\
$\quad$ Occipital & 1 & \\
$\quad$ Maxillary & 2 & \\
$\quad$ Temporal & 3 & \\
$\quad$ Others & & \\
& 15 & $57 \%$ \\
Dizziness/vertigo & 14 & $53 \%$ \\
Nausea/vomiting & 12 & $46 \%$ \\
Unilateral facial numbness & 11 & $42 \%$ \\
Unsteadiness & 6 & $23 \%$ \\
Diplopia & 4 & $15 \%$ \\
Dysarthria & 3 & $11 \%$ \\
Dysphagia & 3 & $11 \%$ \\
Limbs numbness & 3 & $11 \%$ \\
Limb weakness & & \\
& & \\
\hline
\end{tabular}

*combination possible
Table 2: Possible immediate predisposing factors for dissection

\begin{tabular}{lc}
\hline Sports activities: $\mathbf{4}$ patients $\mathbf{( 1 5 \% )}$ & No of patients \\
While playing golf & 1 \\
While playing soccer & 1 \\
While running & 1 \\
While playing baseball & 1
\end{tabular}

$\begin{array}{lc}\text { Associated with chiropractic: } \mathbf{3} \text { patients }(\mathbf{1 1 \%}) & \text { No of patients } \\ \text { During or immediately after chiropractic } & 2 \\ \text { One day after vigorous chiropractic } & 1\end{array}$

Possible neck injury: 7 patients (26 \%)

Snow board accident 12 days prior to stroke

Falling on back one day before

Car accident 2 weeks before

Truck neck accident 3 years previously

Minor neck injury 2 weeks before onset

During loading truck

During vigorous self-manipulation of neck

$$
\text { TOTAL }
$$

No of Patients
1
1
1
1
1
1
1
$14 / 26 \quad 53 \%$

\section{Chronic risk factors}

Hypertension

Diabetes mellitus

Smoking

Migraine
(1) Patients without neurological deficit;

(2) Patients with mild deficits, which did not prevent the patient from performing work and/or major daily activities; for example, slight unsteadiness;

(3) Patients with significant neurological deficit preventing from the performance of work and/or other major activities;

(4) Death.

\section{RESULTS}

\section{Age and Sex}

Of the 26 patients identified, there were 13 men and 13 women. Age ranged between 29 and 76 (mean age 48).

\section{Symptoms}

These were categorized into warning symptoms and cumulative symptoms, Fourteen patients reported having symptoms before onset of stroke. The delay between onset of warning symptoms and stroke onset ranged between 1 to 14 days. The most common warning symptom was headache and neck pain. This was usually of sudden onset, severe and, though not accompanied by other symptoms or signs, persistent until the onset of stroke. With respect to cumulative symptoms assessed in each patient, pain was again the most frequent symptom (22 patients, 84\%). Thirteen patients presented with headache only, four patients with neck pain only and five patients presented with both symptoms. Table 1 summarizes the location of headaches in those patients. 
Table 3: Initial angiographic findings in 25 patients (total dissecting arteries 31 )

\begin{tabular}{lc}
\hline Abnormality & Number of Arteries(\%) \\
Irregular stenosis without occlusion & $17(54 \%)$ \\
Occlusion with stenosis & $13(42 \%)$ \\
Level of dissection: & \\
$\quad$ Extracranial (C1-C2) & $16(51 \%)$ \\
$\quad$ Extracranial (other locations) & $7(22 \%)$ \\
Intracranial dissection & $8(25 \%)$ \\
False aneurysm & $6(19 \%)$ \\
$\quad$ Signs of fibromuscular dysplasia & $2(6 \%)$ \\
& \\
Cerebral angiography of 25 patients with VA dissection: \\
Patients with Unilateral VAdissection & $19(76 \%)$ \\
Patients with Bilateral VA dissection & $6(24 \%)$ \\
\hline
\end{tabular}

\section{Dissection risk factors}

The history revealed a possible link between the onset of dissection and specific predisposing factor in 14 of the patients in this series. This was related to sports activities (four patients), chiropractic maneuvers (three patients) and possible neck injuries in seven patients. The details of the precipitating factors are summarized in Table 2.

\section{Clinical signs on presentation}

Cerebellar signs were the most common objective finding on neurological examination (nine patients). This was unilateral in five patients. Gait ataxia was evident in the remaining four patients. Lateral medullary syndrome signs were present in seven patients, these were partial in five of them. Four patients had visual field abnormalities (two had homonymous hemianopia and two had homonymous quadranopia). Three patients presented with basilar artery syndromes, all had decreased level of consciousness, one of them had Parinaud syndrome and one presented with quadriparesis. There were no clinical findings in three patients - all of them came to medical attention because of vertigo or headache.

\section{Neuroimaging}

In nine patients neuroimaging was normal. Infarction was noted in 17 patients. The most common radiological finding in these patients was cerebellar infarction which was evident in ten patients. The second most common site of involvement was the occipital lobe, which was involved in four patients. Subarachnoid hemorrhage ( $\mathrm{SAH}$ ) was noted in three patients. The dissection was found to be intracranial in all three patients with SAH. Cerebral angiography findings are summarized in Table 3. Two representative images are shown in Figure 1 and 2.

\section{Treatment}

Different treatment modalities were used in our patients according to clinical situation and physician judgment. All three patients who presented with intracranial VAdissection associated with SAH were treated with endovascular occlusion. This was

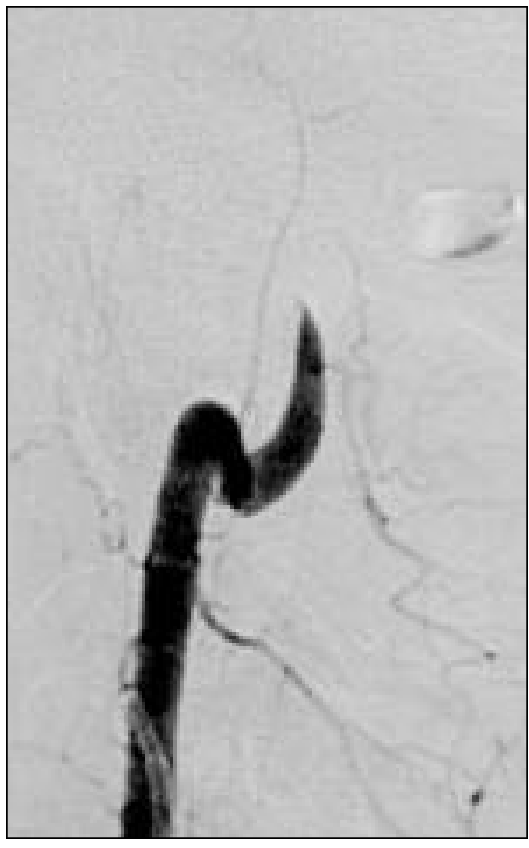

Figure 1: Vertebral artery angiogram, lateral view. There is a smooth conical tapered occlusion of the distal vertebral artery typical of a dissection.
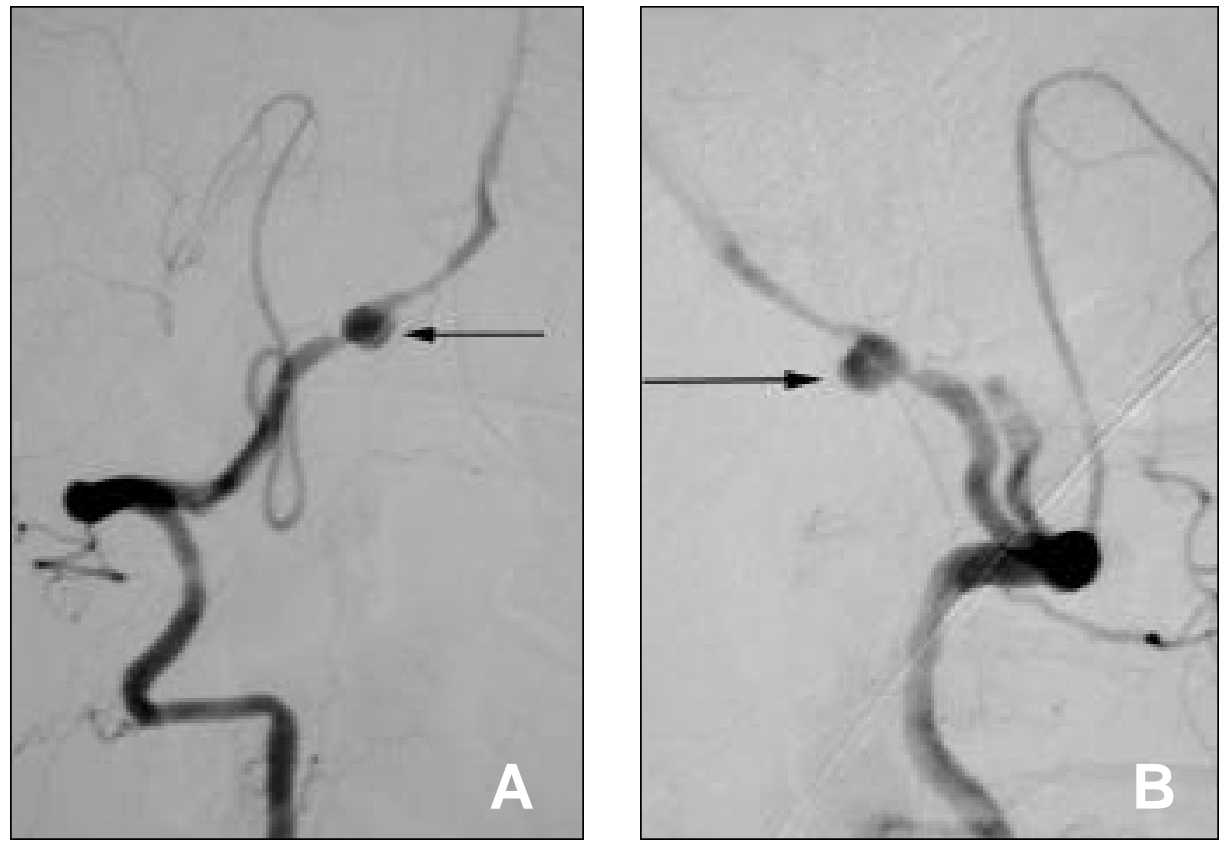

Figure 2: Vertebral artery angiogram A. Frontal view, B. Lateral view. There is a aneurismal dilatation (arrows) of the intracranial portion of the vertebral artery secondary to a dissection. There is a tapered narrowing of the vertebral artery proximal to the aneurysm. This frequently presents with subarachnoid hemorrhage. 


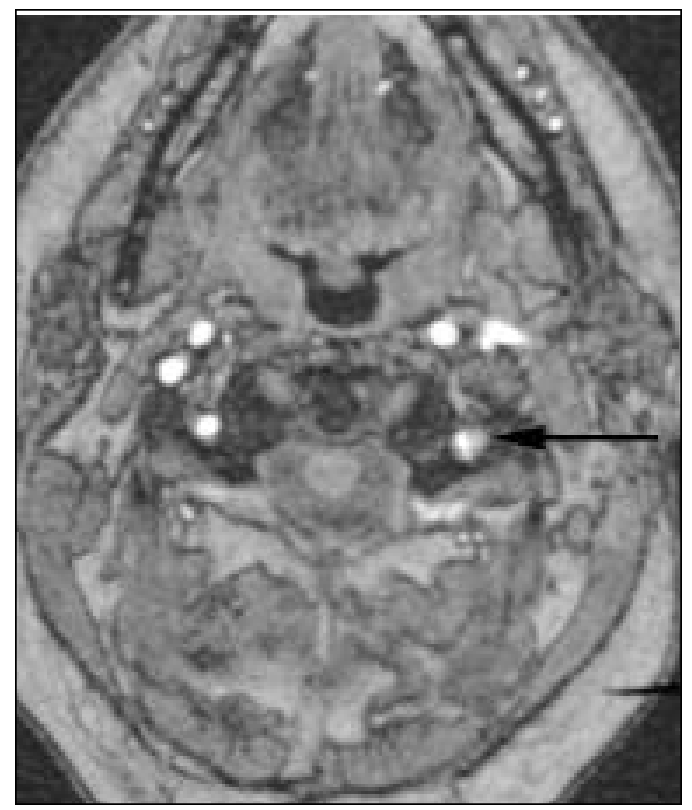

Figure 3: Magnetic resonance angiogram, source image. There is narrowing of the lumen of the left vertebral artery with thrombus within the false lumen (arrow).

followed by surgical clipping of the pseudo-aneurysm in one patient. Two patients (7\%) were treated with intra-arterial thrombolysis. One of these patients presented with signs of basilar artery thrombosis. Cerebral angiography revealed extracranial VA dissection with thrombosis extending to basilar artery. She was treated with intra-arterial t-PA and made an excellent recovery. The other patient had dissection with occlusion of one extracranial VA and hypoplasia of the other artery and developed subacute progressive brain stem signs. She was unsuccessfully treated with intra-arterial Urokinase. Eight patients $(30 \%)$ received antiplatelet agents as the only treatment and 13 patients $(50 \%)$ received anticoagulation treatment. The duration of anticoagulation was very variable. This was for less than a week in four patients, for two months in two patients and for six months in another three patients. The duration of anticoagulation could not be identified in four patients.

\section{Prognosis}

Of the 20 patients who were available for follow-up, eight (40\%) had no residual neurological deficit. Eight patients (40\%) had mild residual symptoms. These consisted of mild imbalance and dizziness in six patients, partial visual field defects in two and difficulty with fine motor movements in one patient. Two patients $(10 \%)$ were left with disabling deficits. Two other patients in our series died in the acute stage. Only two patients (10\%) have had recurrent neurological symptoms that were transient in both cases.

\section{DISCUSSION}

VA dissection is an important cause of stroke in young patients. The incidence of VAdissection is not known precisely. ${ }^{4}$ Once thought to be relatively uncommon, it is now being recognized more frequently. In our series, more than $60 \%$ of the cases studied were diagnosed in the last two years compared to only one patient diagnosed before 1995. During 1998, ten patients with VA dissection were identified in our institute. Although some earlier reports suggested a predominance of VA dissection in females, ${ }^{5,6}$ our data did not show any significant difference in incidence between women and men. With a mean age of 48 , the present study also confirmed that VA dissection mainly affects middle-aged adults.

We found a precipitant factor in 53\% of our patients. Sports activity and chiropractic manipulation were again prominent precipitating factors. After reviewing 90 reported cases of VA dissections in the literature, we found that a similar percentage (49\%) was associated with minor trauma or neck manipulation. ${ }^{2,5,7,8-12}$ It is important to inquire in detail about recent physical activities if arterial dissection is suspected as the etiology of a stroke.

The role of trivial, unnoticed trauma producing dissection is not clear. It has been suggested that patients with "spontaneous" VA dissection may have had unrecognized trauma or sudden neck motion that was forgotten or considered insignificant by the patient and thus not reported to the physician. ${ }^{13}$

Pain in our series was a crucial symptom seen in the majority of patients $(88 \%)$. This was mainly headache with or without neck pain. Typically, the headache was occipital and severe in nature. Our data are consistent with previously reported cases of reported neck pain or headache in $76-100 \%$ of VA dissection patients.

Headache and neck pain were also an important warning sign before the onset of stroke. This was reported by 53\% of the patients, one day to two weeks before the onset of their stroke. Some of the patients had sought medical advice for these early signs. One patient, who presented initially with acute neck pain and vertigo, underwent lumbar puncture to rule out $\mathrm{SAH}$ and then was discharged from hospital, presented later with brain stem infarction.

The extracranial cerebral arteries are known to be pain sensitive $^{14}$ and the pain may be a signal of mural hemorrhage. According to Sturzenegger, ${ }^{3}$ who studied warning symptoms in 44 patients with internal carotid artery dissection, this pain seems to be a key symptom with regard to starting anticoagulation before cerebral infarction has occurred. This may be of similar importance in VA dissection, especially with the observation in our study that $12 \%$ of patients had no abnormal signs on presentation and many presented with minimal signs. Some patients repeatedly presented to the emergency room before developing brainstem or cerebellar strokes. Four other important symptoms reported by about half of our patients were: (1) vertigo; (2) nausea or vomiting; (3) unilateral facial numbness (this symptom was subjective and no abnormality was found by sensory testing); (4) unsteadiness.

Three of our patients presented with SAH due to intracranial segment VA dissection. Their age was relatively older than the other patients $(54,55$ and 76-years-old). Two were diabetic and one was hypertensive. Two patients had a favorable outcome with no significant deficit. However, one patient died due to hydrocephalus and other complications. SAH as a complication of intracranial VA dissection has been reported before in the literature. ${ }^{15-18}$ The proposed mechanism is a dissecting 
hematoma that originates between the media and adventitia. This is more likely to happen in intracranial arteries which lack a well-developed external elastic membrane and have muscularis and adventitial layers that are only about two-thirds as thick as extracranial arteries. ${ }^{17-19}$

Bilateral VA dissection was found in six patients (23\%). This was also found in previous reports in a range between $15 \%$ $61 \%$. $6,8,10,11$ Compared to patients with unilateral VA dissection, patients with bilateral VA dissections tended to have a more severe presentation. Two such patients developed bilateral pontine infarction signs, while another two had cerebellar infarction. One had lateral medullary syndrome and one patient had posterior cerebral artery territory infarction. Multi-vessel involvement in the absence of a history of trauma raises the possibility that an underlying arteriopathy may predispose the vessels to dissection. Only two patients had angiographic evidence of fibromuscular dysplasia. No other vascular abnormalities could be identified. The possibility of an as yet unknown arteriopathy in some of the cases cannot be entirely excluded. $^{6}$

Cerebral angiography was not used as a diagnostic modality in one of our patients. This patient was diagnosed on the basis of his typical clinical presentation, as well as evidence of dissection on MR angiography (Figure 3). Some recent reports suggested that new noninvasive methods, like vertebral Doppler, magnetic resonance imaging and angiography, are useful in detection and monitoring of VA dissection. , $^{9,21}$

The overall prognosis was good on clinical follow-up in the majority of patients. Almost $80 \%$ made complete or near complete recovery. The most important factors associated with unfavorable prognosis (disabling outcome or death) were (1) bilateral dissection; (2) dissection associated with subarachnoid hemorrhage.

The recurrence rate of strokes or transient ischemic attacks was very low, occurring in two patients during the available follow-up period.

In conclusion, VAdissection is increasingly being diagnosed. It mainly affects middle-aged persons and both sexes are equally affected. Headache and/or neck pain are prominent features that may precede onset of stroke by several days. Although the majority of patients will have excellent prognosis, this was less likely in patients presenting with SAH or bilateral VA dissection. Recurrence rate was low.

\section{Acknowledgement}

The authors thank Heather Richardson; Research Co-ordinator, Clinical Trials, University of Alberta Hospital in data collection and Dr. Muzaffar M Siddiqui; Research Fellow, Stroke Research Unit, University of Alberta Hospital for editing this manuscript.

\section{REFERENCES}

1. Schievink WI. Recurrent spontaneous cervical artery dissection. $\mathrm{N}$ Engl J Med 1994;10;330(6) :393-397.

2. Caplan LR. Extracranial vertebral artery disease. In: Caplan LR. Posterior Circulation Ischemia: Clinical Findings, Diagnosis, and Management. Cambridge, MABlackwell Science, 1996:231-258.

3. Sturzenegger M. Spontaneous internal carotid artery dissection: early diagnosis and management in 44 patients. J Neurol 1995; 242:231-238.

4. Hart RG, Easton JD. Dissection and trauma of the cervicocerebral arteries. In: Barnett HJM, Mohr JP, Stien BM, Yatsu FM, eds. Stroke: Pathophysiology, Diagnosis and Management. New York: Churchill Livingston, Inc. 1986:775-788.

5. Chiras J, Marciano S, Vega Molina J, et al. Spontaneous dissecting aneurysm of the extracranial vertebral artery (20 cases). Neuroradiology 1985;27:327-333.

6. Mokri B, Houser OW, Sandok BA, Piepegras DG. Spontaneous dissections of the vertebral arteries. Neurology 1988;38:880-885.

7. Caplan LR, Zarins C, Hemmati M. Spontaneous dissection of the extracranial vertebral arteries. Stroke 1985;16:1030-1038.

8. Mas JL, Bousser M-G, Hasboun D, Laplane D. Extracranial vertebral artery dissections: a review of 13 cases. Stroke 1987; 18:1037-1047.

9. Hoffman M, Sacco RL, Chan S, Mohr JP. Noninvasive detection of vertebral artery dissection. Stroke 1993;24:815-819.

10. Struzenegger M, Mattle HP, Rivoir A, et al. Ultrasound findings in spontaneous extracranial vertebral artery dissection. Stroke 1993; 24:1910-1921.

11. Bartels E, Flugel KA. Evaluation of extracranial vertebral dissection with duplex-flow imaging. Stroke 1996;27:290-295.

12. Josien J. Extracranial vertebral artery dissection: nine cases. J Neurol 1992;239:327-330.

13. Hart RG. Vertebral artery dissection. Neurology 1988;38:987-989.

14. Norregaard TV, Moskowitz MA. Substance P and the sensory innervation of intracranial and extracranial feline cephalic arteries. Brain 1985;108:5170-5233.

15. Caplan LR, Baquis GD, Pessin MS, et al. Dissection of the intracranial vertebral artery. Neurology 1988;38:868-877.

16. Freedman AH, Drake CG. Subarachnoid hemorrhage from intracranial dissecting aneurysm. J Neurosurg 1984;60:325-334.

17. Yonas H, Agamanolis D, Takaoka Y, White RJ. Dissecting intracranial aneurysms. Surg Neurol 1977;8:407-415.

18. Caplan LR, Tettenborn B. Vertebrobasilar occlusive disease: review of selected aspects. 1. Spontaneous dissection of extracranial and intracranial posterior circulation arteries. Cerebrovasc Dis 1992;2:256-265.

19. Anson J, Crowell RM. Cervicocranial arterial dissection. Neurosurgery 1991;29:89-96.

20. Bartels E, Flugel KA. Evaluation of extracranial vertebral artery dissection with duplex-flow imaging. Stroke 1996; 27:290-295.

21. Sturzenegger M, Mattle HP, Rivoir A, et al. Ultrasound findings in spontaneous extracranial vertebral artery dissection. Stroke 1993; 24:1910-1921. 